\title{
REPRESENTAÇÕES SOCIAIS E IDENTIDADE EM GRUPOS DE MULHERES CIGANAS E RURAIS ${ }^{1}$
}

\author{
Mariana Bonomo ${ }^{2}$ \\ Zeidi Araújo Trindade 3 \\ Lídio de Souza ${ }^{4}$ \\ Sabrine Mantuan dos Santos Coutinho ${ }^{5}$
}

Resumo: A partir das teorias da Identidade Social e das Representações Sociais tivemos como objetivo analisar as relações intergrupais estabelecidas entre comunidades rural e cigana, procurando conhecer os significados e as práticas construídas na dinâmica entre endogrupo e exogrupo. Participaram do estudo 17 mulheres de duas comunidades tradicionais, com idades entre 14 e 67 anos. Realizamos entrevistas individuais a partir de roteiros semiestruturados. Procedemos à análise dos dados através do software ALCESTE e da Análise de Conteúdo. Os resultados indicaram presença de práticas que sugerem a existência de elementos de representação ambíguos orientando as relações intergrupais. Discute-se o conflito produzido pela diferenciação identitária ancorada nos elementos das culturas "cigana" e "rural", reforçado por representações dos ciganos como povo amaldiçoado, e os laços de solidariedade gerados pela identidade feminina comum, que agrega o sentimento de mulheres sofredoras e exploradas pelos homens que detêm o poder em ambos os grupos.

Palavras-chave: Identidade social, representação social, relação intergrupal, gênero.

\footnotetext{
${ }^{1}$ Apoio Financeiro: CNPq/CAPES. Endereço de correspondência para o Editor: Mariana Bonomo-marianadalbo@gmail.com.

Programa de Pós-Graduação em Psicologia. Centro de Ciências Humanas e Naturais, Universidade Federal do Espírito Santo. Av. Fernando Ferrari, n. 514 - Campus Universitário Goiabeiras - Vitória, Espírito Santo, Brasil. Cep: 29075-910. Tel: (0xx27) $4009-2501$

2 Doutoranda pelo Programa de Pós-Graduação em Psicologia, Universidade Federal do Espírito Santo. Endereço electrónico: marianadalbo@gmail.com.

${ }^{3}$ Professora do Programa de Pós-Graduação em Psicologia, Universidade Federal do Espírito Santo. Endereço electrónico: zeidi@uol.com.br

${ }^{4}$ Professor do Programa de Pós-Graduação em Psicologia, Universidade Federal do Espírito Santo. Endereço electrónico: lidio.souza@uol.com.br

${ }^{5}$ Doutoranda pelo Programa de Pós-Graduação em Psicologia, Universidade Federal do Espírito Santo. Endereço electrónico: sabrinemsc@hotmail.com
}

PSICOLOGIA, Vol. XXII (1), 2008, Edições Colibri, Lisboa, pp. 153-181. 
Social representations and identity of gypsy and rural women groups (Abstract): From the Social Identity and Social Representations theories, our objective was to analyze the intergroup relations established between rural and gypsy communities, attempting to understand the significations and practices constructed at the in-group and out-group dynamics. Seventeen women from two traditional communities, with ages varying between 14 and 67 years, participated in this study. We performed individual interviews after semi-structured scripts. We analyzed the data through the ALCESTE software and Content Analysis. The results indicated presence of practices that suggest the existence of ambiguous elements of representation guiding the intergroup relations. The conflict produced by the identitary differentiation anchored at the elements of the "Gypsy" and "Rural" cultures, reinforced by representations of gypsies as a cursed people, and the solidarity ties generated by the common feminine identity, that aggregates the feeling of "suffering and exploited women" by men who have the power at both groups.

Keywords: Social identity, social representation, intergroup relation, gender.

\section{Introdução}

As relações entre indivíduo e sociedade são complexas e envolvem uma intrincada rede de fenômenos, entre os quais podemos destacar os sistemas de valores e crenças. Estes sistemas, sempre ancorados na cultura, contribuem para a construção da realidade e orientação das ações dos indivíduos nos diferentes contextos sociais. Pensar as relações intergrupais nesta perspectiva implica considerar o contexto cultural característico de cada grupo social, buscando em seu percurso histórico as estratégias que possibilitaram a construção de determinadas práticas, visto que "não podemos compreender nenhuma realidade social sem conhecer o contexto sócio-histórico em que se envolve" (Casas, 2005, p. 42).

Segundo Bonin (2000), "viver em grupo já é difícil, mas o mais problemático é tentar conviver com grupos que têm diferentes regras de relações e de poderes" (p. 65). Tal é a condição dos grupos rural e cigano, uma vez que suas características culturais se fundamentam em sistemas de crenças e valores marcadamente distintos, que produzem processos identitários também diferentes. Reconhece-se que, no âmbito de cada uma das comunidades, existe diversidade, embora se possa falar de "um rural" e de "um cigano" como categorias, a partir de uma dimensão mais geral da realidade social. A expressão "comunidade" é aqui utilizada para retratar as relações sociais construídas e mantidas por famílias ligadas por laços de parentesco ou não, modos de produção, estratégias de socialização, relações afetivas, crenças e valores partilhados. É nas relações com diferentes grupos que seus 
membros constroem formas de organização familiar e comunitária, buscando coerência entre suas crenças e o modo como efetivamente vivem.

Os primeiros ciganos teriam chegado ao Brasil em 1574, junto com imigrantes e pessoas expulsas de Portugal (IBGE, 2006; Teixeira, 2000). De acordo com representantes da Apreci (Associação de Preservação da Cultura Cigana), estima-se que mais de 500 mil ciganos estejam vivendo atualmente no Brasil, oriundos das três etnias existentes: Rom (proveniente do leste europeu), Sinti (da França, Itália e Alemanha) e Kalom (da Península Ibérica). No entanto, o governo brasileiro ainda não possui dados oficiais acerca da comunidade cigana que vive em seu território, e pouco tem se preocupado com políticas públicas direcionadas a essa população.

Em um estudo realizado por Mendes (2000), que objetivou analisar as fronteiras entre ciganos e não ciganos a partir da identificação de seus sistemas de crenças e regras grupais, encontramos a descrição de algumas formas de organização do grupo. Segundo a autora, o gênero e a idade constituem os eixos fundamentais na estrutura social dos ciganos, mantidos e afirmados principalmente através das mulheres. Os conflitos decorrentes das relações entre grupos ciganos e não ciganos reforçam as regras internas ao grupo, bem como sua rigidez em relação à assimilação de outras formas de funcionamento grupal.

A identidade étnica persiste não só por via da interacção do grupo étnico cigano com outros grupos sociais, mas sobretudo pela oposição entre eles. As diferenças existem e persistem, assim como as oposições, denotando-se nos grupos empíricos uma sobrevalorização defensiva da superioridade moral e social do seu quadro de valores quando em confronto com o dos "Outros". Neste contexto, a valorização simbólica dos valores de práticas sociais do grupo adquire uma forma reactiva e de defesa perante as práticas de exclusão, marginalização e de assimilação de que são alvo e que se inserem num processo de longa duração (Mendes, 2000, sp).

A população brasileira que vive atualmente em áreas rurais, segundo o IBGE, consiste em um quinto da população total, composta por diferentes etnias e sistemas de organização.

Del Priore e Venâncio (2006) destacam que poucos foram os que, de fato, "se debruçaram sobre o destino de lavradores, a vida comunitária, a terra e seus ciclos, tentando iluminar a variedade de modos de vida e de representações sobre o universo rural" (p. 13). A esfera feminina do campo também é parte integrante dessa pluralidade a ser conhecida. As mulheres rurais, de acordo com Brumer (1996), possuem formas variadas de organização, ainda que dentro de um mesmo território. Contudo, o trabalho doméstico e a responsabilidade no cuidado dos filhos são elementos centrais e comuns na vida dessas mulheres: 
"Embora a participação das mulheres varie nessas diferentes sociedades no que diz respeito à sua participação na divisão do trabalho produtivo, existe muita semelhança entre elas no que se refere à sua participação nas atividades de reprodução, tanto as ligadas ao ciclo curto (tais como o trabalho doméstico e as atividades diárias de manutenção), como as relacionadas ao ciclo longo, geracional (tais como a reprodução biológica e educação das crianças) (p. 40).

Dadas as características que possuem, tanto a comunidade cigana quanto a comunidade rural podem ser vistas como grupos marginais, principalmente em contextos predominantemente urbanos e tecnológicos. "É desse modo que determinados povos se transformaram em 'não-ser', em contraposição aos hegemônicos que passaram a 'ser'” (Guareschi, 1998, p. 160).

\section{As Teorias da Identidade Social e das Representações Sociais}

Utilizamos as teorias da Identidade Social (Tajfel, 1982; 1983) e das Representações Sociais (Moscovici, 1978; Jodelet, 2001; 2005) como recursos analíticos para compreender a dinâmica das relações intergrupais estabelecidas entre as comunidades cigana e rural. A utilização conjunta dessas teorias possibilita uma compreensão mais ampla e consistente acerca do fenômeno social estudado, pois

"as representações sociais têm um importante papel na formação de identidades sociais ... as identidades sociais, por outro lado, influenciam a exposição, a aceitação e a utilização de representações sociais que podem influenciar no seu desenvolvimento" (Breakwell, 1993, p. 209).

A representação social pode ser compreendida como "uma forma de conhecimento, socialmente elaborada e partilhada, com um objetivo prático e que contribui para a construção de uma realidade comum a um conjunto social" (Jodelet, 2001, p. 22). Essa "realidade comum" disponibiliza ao indivíduo o patrimônio necessário às identificações e diferenciações sociais a partir de sua afiliação e reconhecimento de pertença a um determinado grupo social. O conceito que o indivíduo tem de si, a construção de sua identidade, portanto,

"deriva do seu conhecimento da sua pertença a um grupo (ou grupos) social, juntamente com o significado emocional e de valor associado àquela pertença" (Tajfel, 1983, p. 290).

O estabelecimento das fronteiras entre quem "somos", ou endogrupo, e quem "não somos", ou exogrupo, permite a compreensão e ordenamento da realidade. É neste processo de categorização social, que decorre da capacidade cognitiva e valorativa que aplicamos ao apreender os elementos dis- 
poníveis nos diversos contextos, que elaboramos nossas representações acerca do outro e de nós mesmos. Essa distinção é mediada pela comparação social que se processa no confronto entre o "próprio grupo" e o "grupo de relação" (Capozza \& Brown, 2000; Tajfel, 1983). As práticas empreendidas pelo próprio grupo e pelos outros grupos com os quais se relaciona são, então, orientadas por uma tendência à atribuição de características e valores negativos aos exogrupos e positivação das características relacionadas ao grupo de pertencimento, bem como uma constante avaliação desta pertença, que podem incluir,

"um componente cognitivo, no sentido em que se sabe que pertence a um grupo; um componente avaliativo, no sentido em que a noção de grupo e/ou de pertença a ele pode ter uma conotação de valor positivo ou negativo; e um componente emocional ... dirigidas para um grupo próprio e para outros com os quais tem certas relações" (Tajfel, 1983, p. 261).

Através das relações grupais, segundo os processos de comparação e categorização social, surgem "as possibilidades de produção de solidariedade e exclusão a partir das identificações sociais" (Souza, 2004, pp. 66-67). Pensar estes processos se mostra relevante, uma vez que as identificações e diferenciações sociais são mediadas por e mediadoras das representações que se tem de determinado grupo social, expressando por excelência

"o espaço do sujeito, em sua relação com a alteridade do mundo, lutando para dar sentido, interpretar e construir os espaços nos quais se encontra" (Jovchelovitch, 2000, p. 81).

Alguns trabalhos (Calil, 2003; Joffe, 1995) permitem discutir como as representações têm força na construção identitária dos indivíduos e como esse sistema de significações atua no comportamento grupal dirigido aos exogrupos; afinal, nos constituímos como sujeitos

"sob a direção dos padrões culturais, sistemas de significados criados historicamente em termos dos quais damos forma, ordem, objetivo e direção às nossas vidas" (Geertz, 1989, p. 37).

A análise de Jodelet (1998) esclarece: O outro, como 'não-eu', 'não-nós', deve ser afastado ou tornar-se estranho pelas características opostas àquelas que exprimem o que é próprio da identidade. $O$ trabalho de elaboração da diferença é orientado para o interior do grupo em termos de proteção; para o exterior, em termos de tipificação desvalorizante e estereotipada do diferente. Nessa construção se movem interesses que servem à comunidade, no interior da qual se define a identidade (p. 51).

Considerando as possíveis articulações entre representações e identidades sociais, evidenciadas na proposta de Breakwell (1993), objetivamos 
neste estudo analisar as relações intergrupais estabelecidas entre mulheres ciganas e mulheres rurais, a partir de uma perspectiva sociocultural, procurando conhecer as representações e práticas construídas nas dinâmicas endo e exogrupais.

\section{Método}

\section{Participantes}

Participaram deste estudo 17 mulheres (10 rurais e 07 ciganas), de duas comunidades tradicionais no interior do Estado do Espírito Santo/Brasil, com idades entre 14 e 67 anos, cujas características estão sistematizadas na Tabela 1 .

Tabela 1: Caracterização das participantes

\begin{tabular}{|c|c|c|c|c|c|c|c|c|c|c|c|}
\hline & \multicolumn{3}{|c|}{ Geração } & \multicolumn{3}{|c|}{ Escolaridade } & \multicolumn{4}{|c|}{ Estado Civil } & \multirow{2}{*}{$\begin{array}{c}\text { Relação do n. }^{\circ} \text { de } \\
\text { filhos entre as } \\
\text { que são mães }\end{array}$} \\
\hline & $1 .^{\mathrm{a}}$ & $2 .^{a}$ & $3 .^{\mathrm{a}}$ & 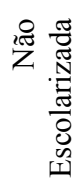 & 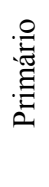 & 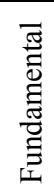 & $\frac{\pi}{2}$ & 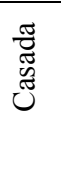 & 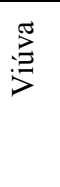 & $\begin{array}{l}\frac{\pi}{0} \\
. \frac{\pi}{0} \\
0 \\
0 \\
0 \\
0 \\
0\end{array}$ & \\
\hline $\begin{array}{c}\text { Mulheres } \\
\text { Ciganas }\end{array}$ & 01 & 01 & 05 & 03 & 04 & - & 02 & 03 & 01 & 01 & 02 a 05 \\
\hline $\begin{array}{c}\text { Mulheres } \\
\text { Rurais }\end{array}$ & 07 & 03 & - & 04 & 04 & 02 & - & 09 & - & 01 & 01 a 07 \\
\hline
\end{tabular}

Nota: Distribuição dos participantes segundo seus grupos de pertencimento (rural e cigano) $(n=17)$.

A comunidade rural onde o estudo foi realizado existe há 49 anos e é constituída por aproximadamente 150 famílias. As duas primeiras gerações de mulheres rurais entrevistadas não nasceram nesta comunidade, sendo provenientes de comunidades vizinhas. Em função de casamento ou imigração da família, mudaram-se para a localidade por volta de finais da década de 1950, época em que a comunidade se estabeleceu como organização sócio-religiosa segundo as Comunidades Eclesiais de Base ${ }^{6}$.

${ }^{6}$ Cf. MAINWARING, S. A igreja católica e a politica no Brasil. São Paulo: Brasiliense, 2004. 
Quanto à comunidade cigana, esta compreende um núcleo composto por 11 famílias, que há dez anos abandonou o nomadismo constante e se fixou no mesmo município que a comunidade rural. Apesar desta mudança, o grupo ainda mantém a prática das "viagens" , como designado pelos próprios ciganos, sendo realizadas a cada dois anos, conforme desejo da comunidade. Todas as mulheres ciganas entrevistadas nasceram no Estado da Bahia/Brasil e, em função das regras do grupo, acompanharam a família do marido, que desenvolve atividades econômicas no Estado do Espírito Santo.

Estas comunidades estão em contato há vários anos, o que tem permitido a difusão de representações que cada grupo tem sobre o outro, tanto entre as gerações de ambos os grupos que vivenciaram a época das viagens ciganas, quanto entre as novas gerações ciganas e rurais.

\section{Procedimento de coleta dos dados e instrumento}

As entrevistas foram realizadas nas próprias comunidades dos grupos rural e cigano. As mulheres rurais foram contatadas diretamente em suas casas $^{8}$, no momento em que realizamos as entrevistas. Na comunidade cigana, pedimos primeiramente autorização ao chefe do grupo, seguindo orientação do morador da primeira residência ${ }^{9}$ que visitamos. A partir do acolhimento do grupo à proposta de realização da pesquisa, visitamos cada barraca da comunidade, entrevistando individualmente as ciganas. Conforme acordado com cada participante, todas as entrevistas foram gravadas e posteriormente transcritas integralmente, para processamento das informações obtidas.

Nas entrevistas com as mulheres ciganas, um dos homens da comunidade permanecia durante os primeiros momentos, geralmente durante a identificação da participante. Ao término da entrevista, um dos ciganos pedia para ouvir a gravação. Seguindo as normas éticas que regulam a pesquisa com humanos, evitou-se que as entrevistas fossem ouvidas pelos homens ciganos a partir de uma negociação com estes últimos. Entendemos que a postura dos ciganos funciona mais como estratégia de proteção do grupo em relação às pessoas estranhas à comunidade, do que como coação às mulheres ciganas para que não externalizem críticas sobre a realidade da

\footnotetext{
${ }^{7}$ As viagens se caracterizam por deslocamentos periódicos e temporários que a comunidade realiza, embora mantenha a base de moradia.

8 O termo "casa" é utilizado em relação à comunidade rural tanto para se referir a casa-estabelecimento quanto ao território que circunscreve o patrimônio daquela pessoa. Desta forma, quando alguém diz "fui à sua casa", não significa que a pessoa necessariamente tenha entrado na casa-estabelecimento, mas que esteve em seu território.

9 Como a comunidade cigana denomina suas residências de "barraca", utilizaremos tal nomeação para nos referirmos às moradias ciganas.
} 
comunidade. Não descartamos, no entanto, a possibilidade de que tal fato tenha influenciado o conteúdo das entrevistas das mulheres, embora, como veremos adiante, os dados tenham revelado elementos avaliativos acerca das relações de gênero vivenciadas no grupo cigano.

Uma outra consideração importante acerca da comunidade cigana é que, além do português (língua utilizada no cotidiano do grupo), eles possuem uma língua (chiba) própria, o romani, que também funciona como estratégia de proteção do grupo contra pessoas estranhas, o que acarretou, inicialmente, certa dificuldade de comunicação. Além disso, temos que considerar que a pesquisadora que realizou a coleta de dados com todas as entrevistadas era uma pessoa estranha à comunidade; utilizava o gravador, objeto não familiar ao grupo, para o registro das entrevistas; e, mais do que isso, convidou as mulheres da comunidade para falar sobre o cotidiano e práticas dos ciganos, o que geralmente é feito pelos homens.

A fim de criarmos uma relação mais familiar com os grupos pesquisados, utilizamos a estratégia de um roteiro temático com estruturação invisível (Nicolaci-da-Costa, 1989). O roteiro constava de três partes: 1. Dados pessoais da participante; 2. Questões contemplando o universo do endogrupo (sobre a comunidade e a vida da mulher pertencente àquele grupo), e 3 . Questões acerca do exogrupo em comparação com o endogrupo (sentimentos, percepções e experiências referentes ao grupo de relação).

\section{Procedimentos de Análise dos Dados}

Utilizamos dois recursos complementares para a análise do material coletado: o software ALCESTE e a Análise de Conteúdo. A partir do uso de um mesmo banco de dados, o emprego conjugado do ALCESTE e da Análise de Conteúdo pode "resultar em ganhos concretos em relação à utilização de apenas uma dessas alternativas de análise" (Nascimento, 2004, p. 43). Este software tem sido usado em diferentes trabalhos sobre Representações Sociais (Martins, 2002; Menandro, 2004; Nascimento, 2004) e também no campo de estudo das Identidades Sociais (Ribeiro, 2005).

$\mathrm{O}$ processamento das entrevistas foi realizado primeiramente através do ALCESTE (Analyse Lexicale par Contexte d'um Ensemble de Segments de Texte), com o objetivo de termos uma dimensão mais geral do corpus de dados que compõe nosso material de análise. Este software foi desenvolvido por Reinert (1990), sendo considerado uma metodologia

"pelo fato de integrar métodos estatísticos sofisticados, se ajustando ao objetivo de análise a que se propõe" (Menandro, 2004, p. 94).

Através de um banco de dados composto de conjuntos de textos (no nosso caso, entrevistas), o ALCESTE realiza a organização desse material segundo suas unidades básicas de análise. São elas: Unidades de Contexto 
Iniciais (UCI) - primeira divisão de todo o material, sendo realizada durante a preparação do corpus (cada entrevista é uma UCI) - e Unidades de Contexto Elementares (UCE) - fragmentos do corpus organizados pelo programa, de acordo com critério de pontuação e tamanho do texto. A partir da identificação das unidades, o programa efetua uma Classificação Hierárquica Descendente (CHD) do conjunto de unidades contextuais, gerando um dendrograma (posicionamento das classes em forma de árvore) que permite a visualização da análise estatística realizada, com freqüência das palavras representativas em cada classe, força de ligação entre as classes e porcentagem de cada classe em meio ao corpus analisado. O ALCESTE realiza ainda uma Análise Fatorial de Correspondência (AFC) entre as variáveis determinadas pelo pesquisador (idade, sexo, inserção social, grupo A ou B, entre outros) e as classes geradas pelo programa. $\mathrm{Na}$ apresentação dos resultados referentes à presente pesquisa, focalizaremos apenas a Classificação Hierárquica Descendente.

No processamento das informações que coletamos, construímos dois corpora de dados para análise do ALCESTE, usando as 17 entrevistas. Desta forma, submetemos separadamente ao software ALCESTE o corpus referente às mulheres rurais e o corpus relativo às mulheres ciganas, tendo sido gerados dois dendrogramas para cada um dos grupos analisados.

Para a Análise de Conteúdo (Bardin, 2002; Bauer, 2002; Flick, 2004) também consideramos todas as entrevistas realizadas. Procedemos à análise dos dados coletados a partir da identificação de unidades de significado mais gerais relacionadas a núcleos temáticos considerados importantes para a apreensão das relações intergrupais:

Representações endo e exogrupais - mulheres ciganas e mulheres rurais; Representações endo e exogrupais - homens e mulheres; A dinâmica intergrupal entre a casa e a barraca; Ancoragens do medo de ciganos.

\section{Resultados}

Os resultados apresentados a seguir devem ser analisados com cautela, visto que, em função das dificuldades de acesso às participantes, não foi possível homogeneizar os grupos com base nas variáveis possivelmente relevantes. Além disso, é importante reafirmar que o interesse principal do estudo foi compreender a importância da identificação grupal nas relações intergrupais.

Apresentamos primeiramente os resultados obtidos através da análise do ALCESTE, segundo os grupos "rural" e "cigano", respectivamente. Posteriormente, descrevemos as Unidades de Significados elaboradas a partir da Análise de Conteúdo. 


\section{Análise dos grupos rural e cigano através do ALCESTE}

A análise textual realizada pelo ALCESTE através das unidades de contexto possibilita "reconstruir o discurso coletivo, a partir da relação entre as palavras, a freqüência com que aparecem e suas associações em classes de palavras" (Cuvello, 2004, p. 75). De acordo com Nascimento (2004), a relação entre estas unidades de contexto e os contextos típicos (representação coletiva) congrega a base do funcionamento do ALCESTE, uma vez que

"a regularidade de representações entre indivíduos pode promover a existência de um contexto típico de um grupo: uma representação coletiva, um mundo" (Nascimento, 2004, p. 45).

Apresentamos a seguir os dendrogramas e fragmentos de texto (UCE) referentes a cada um dos grupos analisados. Cada classe do dendrograma é composta por um conjunto de 15 palavras, selecionadas a partir do valor do qui-quadrado (seqüenciadas segundo ordem decrescente), que é considerado um indicador de associação. Para entender a relação entre as classes é interessante observar o índice de relação entre elas, sendo que valores acima de 0,5 indicam maior força de ligação (Menandro, 2004).

\section{Grupo de Mulheres Rurais}

Das 10 UCI (entrevistas) do grupo de mulheres rurais, o software ALCESTE registrou 294 UCE, tendo sido analisado 69,83\% do corpus. Tivemos uma divisão em dois eixos distintos, cada um deles contendo três classes. A análise do material do grupo rural permitiu a disposição dessas classes em função do discurso endogrupal e exogrupal, como organizado nos dois grandes eixos gerados pelo ALCESTE. A Figura 1 apresenta tal configuração e a força da ligação entre as classes sugeridas pelo software.

No primeiro eixo observamos a existência de uma forte ligação entre as classes 1 e $3(r=0,54)$ e no segundo eixo entre as classes 2 e $4(r=0,72)$. Comparando o índice de ligação entre as classes que compõem o eixo exogrupo com o eixo endogrupo, podemos identificar maior força de relação neste segundo eixo $(r=0,65)$, enquanto a força de ligação para o discurso exogrupo é menor $(r=0,32)$, o que indica maior coesão do discurso endogrupo. 


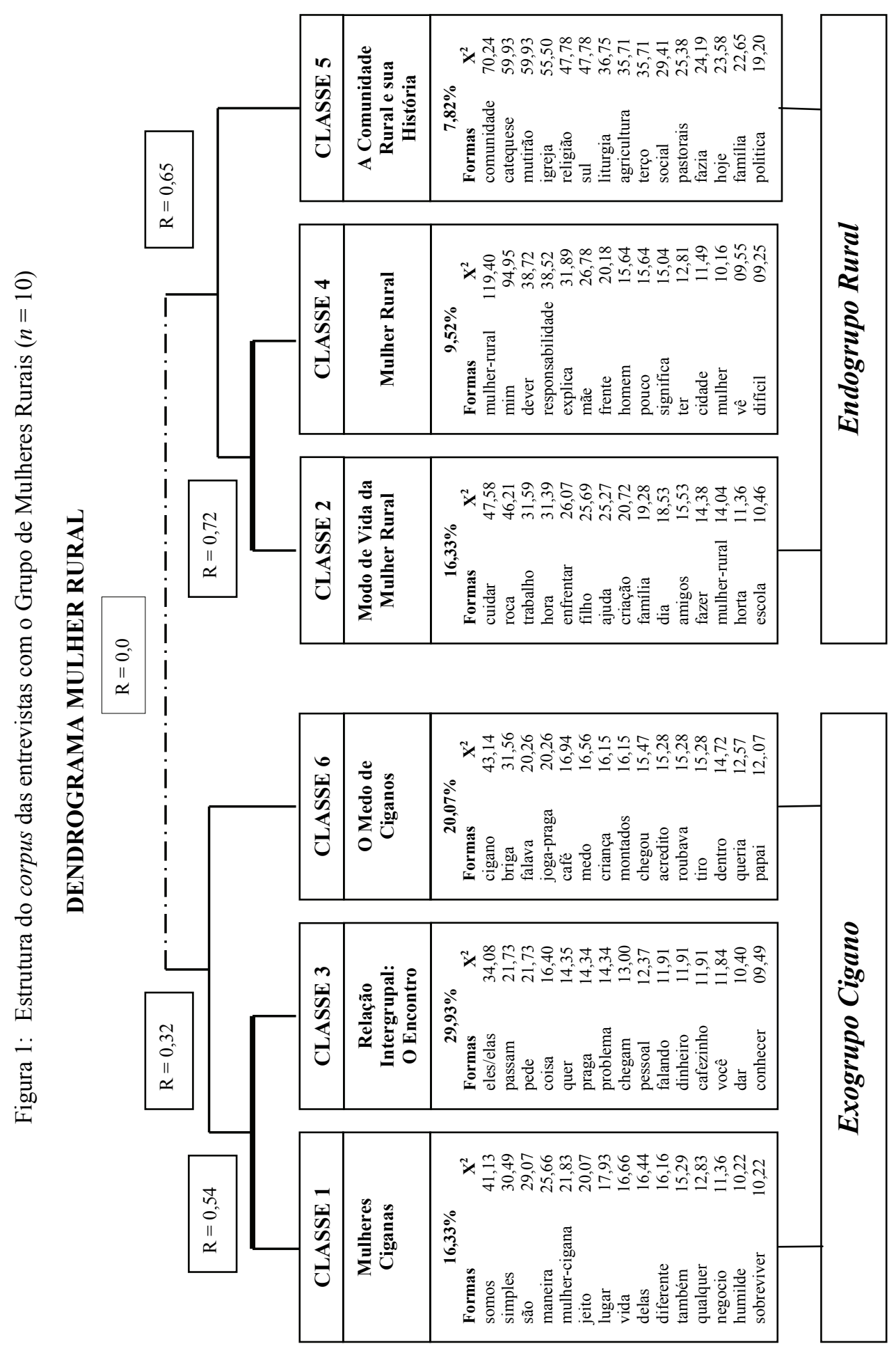




\section{Eixo Exogrupo}

Este eixo concentra $66,33 \%$ do corpus analisado e corresponde ao discurso referente ao grupo cigano. Na Classe 1 encontramos conteúdos relacionados às representações de "Mulher Cigana". As mulheres rurais associam os elementos positivos que configuram o que é "ser mulher cigana" às características que percebem como compartilhadas com seu próprio grupo. A vida simples e humilde vivida por ambos os grupos são pontos comuns apresentados: "Eu acharia que devia ser igual à gente mesmo. Eu acho que é simples também". Contudo, o ponto central de identificação entre os grupos vincula-se ao sentimento compartilhado de "mulheres exploradas", cujos papéis assumidos na relação com os homens se enquadram numa condição de submissão:

"Mas são mais exploradas ainda do que nós as mulheres ciganas. Debaixo de chuva, aqueles trem tudo que molha, aquela sujeira. Eu acho que é complicada. Eu imagino que a vida de uma mulher cigana é complicada porque tem que estar abaixo do cigano."

As diferenças e estranhamentos são apontados quanto aos hábitos e costumes das ciganas em suas características culturais como as roupas e a prática do pedir -

"Sempre alegre. Andam com aquelas roupas compridas, cabelo grande e solto. São diferentes. O jeito delas é pedir... de pedir eles não larga não. $E$ costume"

- e também na clássica imagem da mulher cigana como desprovida de hábitos de higiene:

"Elas andam de qualquer maneira. Elas as vez, até toma banho e troca de roupa, mas as roupas delas é lavada assim... nem imagino como, de qualquer maneira."

A Classe 3, "Relação Intergrupal", explicita o lugar do estrangeiro, suspeito e pouco confiável:

"É igual quando a gente vê uma pessoa estranha, que você não conhece, vocêfica com medo. Porque você não conhece aquela pessoa, vem de fora."

O grupo cigano, no entanto, além de estranho à comunidade rural, é construído no imaginário deste grupo como pleno de poderes místicos que se contrapõem às rezas cristãs, entendidas pelo grupo rural como a única forma legítima de contato com a divindade. Eles tornam-se assim os eternos estrangeiros de lugares já bem conhecidos:

"Mas não deixa de dar aquele arrepio quando a cigana chega perto. Vem querer benzer, a gente. Eu sempre que encontro com elas, que elas vêm querer benzer, eu não quero." 
Numa tentativa de ultrapassar a condição de grupo excluído, o grupo cigano se utiliza de cortesia para conquistar o grupo rural -

"Elas chamam pra dentro, quer dar cafezinho, trata a gente bem mesmo. Pra agradar a pessoa. Fazer união com eles. Elas precisam das mulheres rurais. Elas precisam das mulheres rurais pra ajudar elas."

As idéias centrais presentes na Classe 6, "O Medo de Ciganos", correspondem aos elementos construídos pelas imagens deste grupo como povo amaldiçoado. Ao longo das três gerações a comunidade rural nutriu-se de um medo decorrente de experiências negativas vividas no encontro entre os grupos, que foi sendo transmitido a cada nova geração:

"Eu acho que medo porque desde criança papai falava que cigano... Cuidado com cigano! Cuidado com cigano! Papai falava: cigano está por ai. Cuidado. Eles só mandavam tomar cuidado. Mas a gente já ficava com medo porque sabia que eles roubavam mesmo. Uma vez, roubaram as roupas da mamãe todinha."

Práticas de proteção contra o grupo cigano, como fechar a casa e ter mais cuidado com os filhos, eram imediatamente enfatizadas pelas mulheres rurais:

"Elas passaram, e eu tinha muito medo de cigano, elas passaram ali embaixo. Eu fechei a casa e sentei na beira do paiol, na beira da estrada. Eu e meus meninos pequenos. Ela passou e me pediu, alguma coisa. Eu falei que eu não morava lá não. Ela me jogou praga."

Dar alguma coisa a alguém pode ser entendido como uma forma de expressar solidariedade, de estabelecer laços de humanidade, o que não se configura quando as mulheres rurais fazem doações às ciganas. Como a imagem das mulheres ciganas está vinculada à idéia do mal, do poder de fazer o mal através de pragas e atos nocivos, a doação tem por objetivo não lhes despertar a raiva e também se livrar de sua presença, revelando práticas de exclusão.

\section{Eixo Endogrupo}

Este eixo reúne conteúdos que contemplam o próprio grupo rural. A Classe 2 e a Classe 4 focalizam as práticas e representações acerca da mulher rural. O "Modo de Vida da Mulher Rural" refere-se às práticas desempenhadas em sua rotina entre a casa e o roçado, o cuidado com os filhos e o marido -

" $A$ vida da mulher rural é que a gente levanta cedo vai cuidar das criação, primeiro cuida dos filhos, quando tem pequeno... cuida dos filhos, cuida da casa, cuida da criação, depois vai pra roça. Cuida na roça, vem pra casa, a gente tem que saber que tem as orações, no meio também que entra, tem que cuidar dos filhos, ensinar rezar, trabalhar, levar na escola." 
- e as atividades da comunidade -

"Depois ainda tem o tempo pra comunidade. então, a gente encontra também o momento de encontrar com os amigos, na comunidade, na escola, talvez vai numa reunião."

Ser mulher rural (Classe 4) é "ser comprometida, ter responsabilidade, e saber educar a família". Isto torna a mulher uma figura central no funcionamento familiar e comunitário:

"Ai de um homem que não tiver uma mulher, ai de um filho que não tiver uma mãe. Ai da comunidade se não fosse as mulheres."

Na Classe 5 "A Comunidade Rural e sua história" encontramos os elementos que traduzem o contexto do mundo rural:

"São agricultores e organizados, tem a igreja, tem escola, tem lazer, tem as vendinhas, tem uma porção de coisa organizada já na comunidade."

A história da comunidade está marcada pela forte relação de solidariedade, que permitiu a construção da estrutura física, social e religiosa, sobretudo no início da comunidade, quando esta reunia migrantes do sul do estado empenhados na construção de um lugar para viverem:

"O ponto mais bonito do início da comunidade foi quando se trabalhava em mutirão. As famílias da comunidade eram poucas, mas as poucas famílias se tornavam muitas por conta do mutirão que se fazia."

\section{Grupo de Mulheres Ciganas}

A partir da análise das 07 UCI (entrevistas) do grupo de mulheres ciganas, o software ALCESTE registrou 129 UCE com índice percentual do material analisado de $68,98 \%$, o que indica uma significativa consistência do corpus processado (tal como encontrado no corpus do grupo rural). $\mathrm{O}$ resultado dessa análise indicou a presença de três grandes eixos: Exogrupo, Endogrupo e Prática Mística. Na Figura 2, podemos observar a organização dos eixos e classes. 


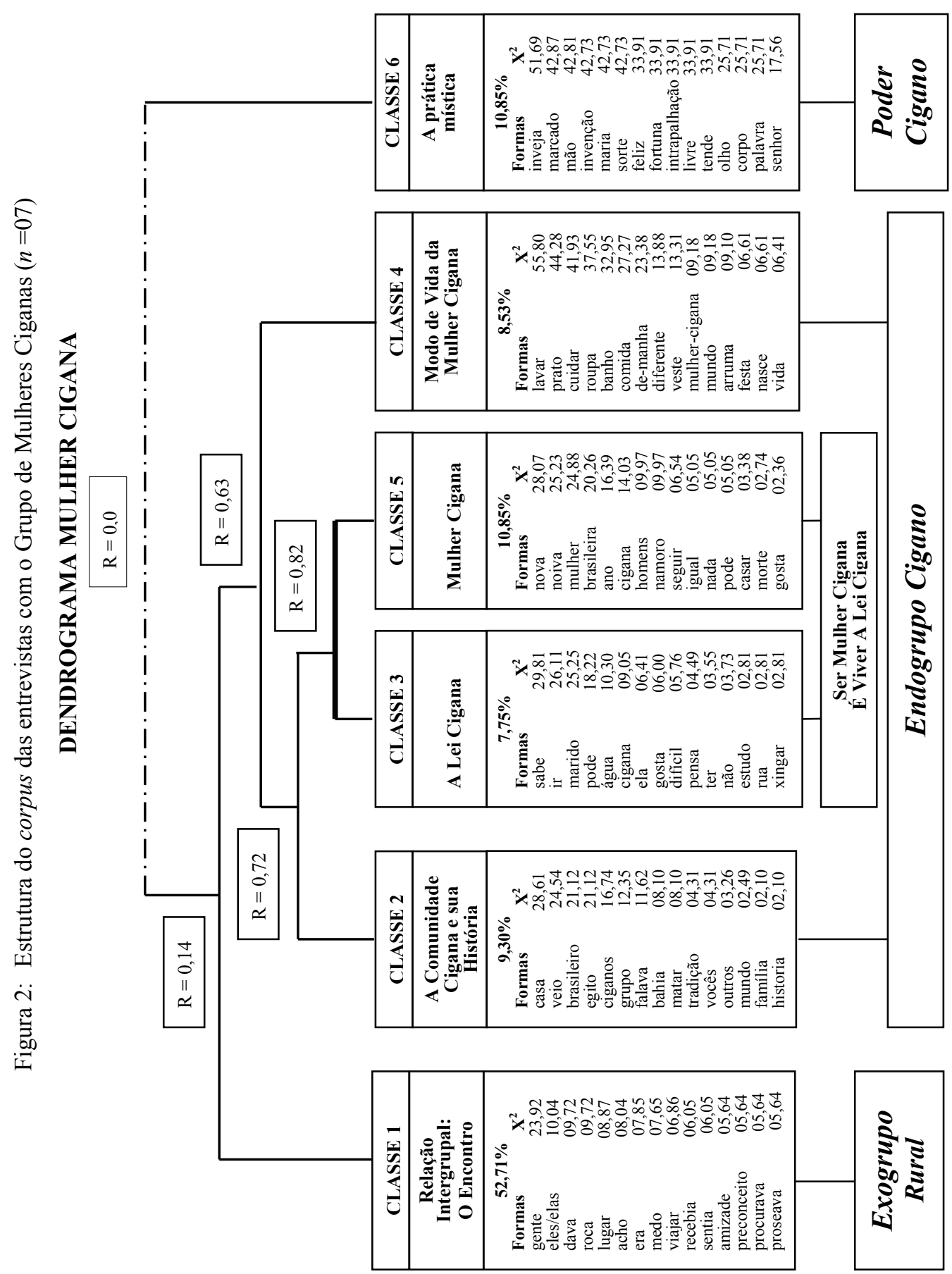


No segundo eixo observamos que existe uma forte ligação entre as classes $2,3,5$ e $4(r=0,63)$, que compõem o eixo endogrupo, tendo as classes 3 e 5 um maior índice de proximidade $(r=0,82)$.

\section{Eixo Exogrupo}

Corresponde a $52,71 \%$ do material analisado e apresenta uma única classe. Esse eixo corresponde ao discurso Exogrupo referente à "Relação Intergrupal" estabelecida entre as comunidades cigana e rural. As dificuldades inerentes à vida nômade, característica da comunidade cigana, são intensificadas pela valorização negativa dos grupos estáticos:

"Quando pedia um canto e eles não dava, ia caçar um muito longe pra ficar".

Como a função de aquisição dos recursos para a manutenção do grupo durante as viagens é das mulheres ciganas, são principalmente elas que enfrentam o preconceito, efeito do medo sentido pelo exogrupo rural:

"Tinha umas mulheres que fechavam as portas. Elas falavam vem cigano! Vem cigano. E não davam atenção à gente, ficava com medo. A gente sentia vergonha, sentia mal. Eu acho que tinha medo porque elas nunca tinham visto... Ficava assustada mesmo."

O grupo, tradicionalmente com passagem rápida pelos lugares, buscava na possibilidade de troca o meio de conseguir o que precisava:

"Nós tratava boa. Eu chamava pra dentro, dava atenção, conversava porque nós não tem cisma, nós tem amizade com todo mundo. Depois ia embora. Ai a gente dava negócio a ela, ela dava com a gente".

\section{Eixo Endogrupo}

Este eixo é composto de quatro classes: "A Comunidade Cigana e sua História", "A Lei Cigana", "Modo de Vida da Mulher Cigana" e "Mulher Cigana". A Classe 2, "A Comunidade Cigana e sua História", reflete o contexto da comunidade e sua forma de organização, a partir de sua história e formação grupal. As identidades "cigana" e "brasileira" se confundem, ora sendo tomadas como identidades comuns, ora servindo de fronteira para designar quem é cigano e quem não é -

"O nosso grupo, os mais velhos diz que veio do Egito. Mas nós não somos mais do Egito, nós somos aqui do Brasil mesmo".

Ser brasileiro e católico são estratégias de identificação utilizadas pelo grupo cigano, formas de inserção na lógica corrente, em busca de 
reconhecimento e aceitação por parte dos grupos com os quais se relacionam -

"Pra formar o casamento, casa igual a vocês. Casa no 'pade', na igreja."

Contudo, embora conjugue elementos não ciganos, o ritual do casamento é tido como um dos maiores acontecimentos da comunidade cigana, possuindo regras próprias que são rigorosamente mantidas, sobretudo, quanto à conduta feminina -

"E tem a história que a cigana só tem que casar virgem. Tem que casar virgem. A moça mesmo tem que casar virgem de ciganos. Tem que provar pra todo mundo ver. Meu casamento foi uma festa boa. Foi matado gado, foram cinco dias de festa".

São as leis ciganas que regem o que é ser mulher cigana e as práticas a elas atribuídas:

"não pode namorar com quem não é cigano, sabe? Não pode ir no caso de quem não é cigano, não sai com quem não é cigano. [...] Mulher de cigano, cigana não gosta de farra de rua, não gosta de passear, assim. Não gosta de bar" (Classe 3).

O cotidiano da mulher cigana, portanto, como pode ser conferido na Classe 4, está marcado pela vida caracteristicamente doméstica, tendo como universo a barraca -

"Mulher cigana, dá de manhã, lava suas vasilhas, coa café, como toda mulher dona de casa, arrumar suas coisas, dá na hora do almoço, faz sua comida, lava seus pratos, varre a barraca [...] O dia-a-dia é lavar roupa, não todo dia. Dia sim, dia não. Cuidar da comida, lavar vasilha, depois tomar banho e assistir novela".

As regras do grupo, a história da comunidade e a vida das mulheres estão fortemente ligadas. Vivem sob as rígidas leis que regem principalmente a conduta das mulheres, contraditoriamente denunciando essa desigualdade, mas sem se referir à possibilidade de mudança -

"Eu não mudaria nada no grupo. Ser eu mesma. Eu não gosto de ser mulher não. Mulher sofre mais do que os homens...[...] Na lei do cigano tem que morar longe. Na lei do cigano, cigana não pode namorar, só eles; cigana não pode casar com brasileiro, só eles; eles pode ir pra rua."

Suas práticas advêm dos princípios basilares que são culturalmente demarcados, sem a possibilidade de discuti-los. As sanções são difundidas entre as mulheres, que se utilizam de exemplos de uma prima ou uma amiga que foi morta por ter desobedecido à lei. Desta forma, ser "Mulher Cigana" (Classe 5) está alicerçado numa vida programada pela tradição sob aspectos que lhe permitem poucas escolhas - 
"Cigana casa nova... ai pode ter filho. Meu casamento foi bom, prometido desde criança. Conhecia muito pouco meu noivo. A minha história foi que nós se gostemos e ai nós se casemos. Nós é prometido de pequeno, de novinho".

Assim que o desenvolvimento corporal permitir, ou às vezes nem obedecendo tais limites, as jovens ciganas seguem a tradição do casamento, cumprindo sua função e reforçando as leis que regem o grupo -

"Mulher de verdade? É a menstruação. Quando está pra vim a menstruação, ai que é mulher e pode casar. Nós ciganas casa nova, novinha. Independente de ter menstruado. Eu casei com treze anos. Ai pode ter filho".

\section{Eixo A Prática Mística}

Compõe essa classe a oração cigana de proteção e leitura da mão. Esse eixo é constituído basicamente pelo conteúdo da entrevista realizada com a cigana mais velha da comunidade. Ao perguntarmos o que é ser mulher cigana, ela buscou responder através de sua prática, procedendo à evocação das palavras místicas que lhe foram ensinadas pelas ciganas de gerações passadas:

"Eu achei essa cabocla que vai me dar essa oração, guardando meu corpo me livrando da inveja, da invenção, do olho ruim e da intrapalhação. Hoje neste dia com as três palavras de Deus e da virgem Maria, meu corpo tá fechado me livrando de ponta de faca, de arma de fogo e de prisão.[...] Eu hei de ser feliz no meu casamento, sem inveja, sem invenção, sem olho ruim e sem intrapalhação. [...] Senhor anda de ronda seu boiadeiro que vai abrir meus caminhos pra eu ser feliz".

Este conteúdo é o patrimônio simbólico utilizado pelas ciganas em seus encontros com os exogrupos. Através do poder de prever o futuro, das promessas de sorte, fortuna e de uma vida feliz, elas realizavam as barganhas nos lugares onde passavam. Contudo, esse "poder da magia" é visto pelas mulheres rurais como carregado de suspeitas, uma vez que as graças e milagres de Deus só poderiam vir através dos mecanismos conhecidos e partilhados pelas crenças do endogrupo rural.

\section{Análise de Conteúdo}

Realizamos a Análise de Conteúdo como uma forma de análise complementar, através da análise temática, que

“consiste em descobrir os 'núcleos de sentido' que compõem a comunicação e cuja presença, ou freqüência de aparição, podem significar alguma coisa para o objectivo analítico escolhido" (Bardin, 2002, p. 105). 
De acordo a autora, a identificação dos temas através das unidades de significação é utilizada em estudos de crenças, valores, tendências ou motivação de opinião, onde o tema

"é a unidade de significação que se liberta naturalmente de um texto analisado segundo certos critérios relativos à teoria que serve de guia à leitura" (p. 105). rurais

a) Representações endo e exogrupais - mulheres ciganas e mulheres

Apresentamos na Tabela 2 os elementos das representações explicitadas pelos grupos rural e cigano quanto às identificações em relação ao próprio grupo e ao grupo de relação:

Comparando os dados da Tabela 2 com os da análise realizada pelo ALCESTE, encontramos representações semelhantes. Contudo, as representações das mulheres ciganas sobre as mulheres rurais foram identificadas de forma mais clara através da Análise de Conteúdo (ver Tabela 2).

Os elementos da vida cotidiana, constituídos principalmente pelas atividades domésticas, foram enfatizados por ambos os grupos. Enquanto as mulheres rurais enfatizaram o trabalho agrário e a participação na comunidade como aspectos importantes do seu modo de vida, as mulheres ciganas destacaram o ritual do casamento e as regras de comportamento.

Tabela 2: Representações sobre endo e exogrupo - mulheres ciganas e rurais

\begin{tabular}{|c|c|c|}
\hline \multicolumn{2}{|c|}{ GRUPOS } & REPRESENTAÇÕES \\
\hline 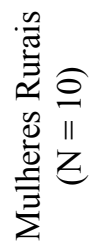 & Endogrupo & $\begin{array}{l}\text { Batalhadoras, cuidam da casa e do marido, dispostas, } \\
\text { honestas, humildes, justas, mães, solidárias. }\end{array}$ \\
\hline 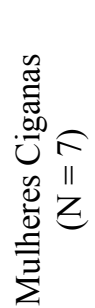 & Endogrupo & $\begin{array}{l}\text { Valorizam normas conjugais, amigas, donas de casa, } \\
\text { comprometidas, não namoram, não trabalham fora, } \\
\text { usam roupas típicas, vergonhosas com homens, têm } \\
\text { vida boa, respeito, não têm amizade com estranhos, } \\
\text { não gostam de rua, organizadas. } \\
\text { Caseiras, conversam com todos, gente ruim, igno- } \\
\text { rantes, namoram, não têm respeito, trabalham na roça. }\end{array}$ \\
\hline
\end{tabular}

Nota: Foram considerados apenas os elementos de representação mencionados por, no mínimo, duas participantes.

"É boa porque, apesar de que tem muito servicinho de fazer, mas é muito gostosa. Você acorda cedo, você sabe que você tem que cuidar do almoço, 
das criação, da sua horta, depois ainda sobra um tempinho pra ir pra roça. Ai a gente cuida da familia.... tudo bem dividido, tem tempinho pra tudo. Depois ainda tem o tempinho pra comunidade. Então, a gente encontra também o momento de encontrar com os amigos, na comunidade, na escola, talvez vai numa reunião... pra tudo a gente tem um tempo. Então ser mulher da roça é isso ai". (Mulher rural, 52 anos).

“Mulher cigana é o seguinte... é porque a nossa tradição... porque cigano não namora, não tem negócio de beijo, negócio de sair com o noivo... enoivou? Tem uns que marcam com um ano, que tem mais condições, marca com um ano, dois anos... no máximo um ano e meio pra baixo. Ai marca aquela data do casamento [...] é ser dona de casa é como eu estou lhe falando... é ser organizada, saber fazer suas coisas, organizada na comida, seu vestuário é assim mesmo... veste saia, agora shortinho não veste, calça é muito dificil, e de vestido comprido. É casar e viver a vida em paz, com fé em Deus. O dia-a-dia é lavar roupa, não todo dia... dia sim, dia não, cuidar da comida, lavar vasilha, depois tomar banho e sisti novela". (Mulher cigana, 38 anos).

As representações, tanto das mulheres rurais quanto das ciganas em relação ao exogrupo, marcam as diferenças culturais e indicam os conflitos enfrentados por elas nos encontros.

"É diferente, né, a gente fica assim, mais... a cigana parece que é diferente o modo delas conversar, o modo delas sentar, elas... é totalmente diferente. Elas chegam na casa da gente, já chega pedindo. Pede pra você dar uma coisa, pede outra, pede outra, quer ler a sorte, fala que quer ler a mão da gente, e se a gente não quiser elas insiste... e a gente não aceita pra ler". (Mulher rural, 54 anos).

"Eu acho que elas também não é muito... é mulher mais caseira, já é criada na roça mesmo, só mais pra trabalhar". (Mulher cigana, 38 anos).

"Elas são mulheres caseiras, não sai... Eu acho que é muito trabalhoso, pois que é de roça.... Eu acho ruim o jeito delas tratarem a gente. São ignorantes". (Mulher cigana, 19 anos).

Essa relação conflituosa está alicerçada principalmente no medo dos ciganos pelo grupo rural, associando-os ao furto e ao poder da maldição:

"Eu acho que é terrível porque vivia pela casa dos outros pedindo, roubando, igual elas roubaram minhas galinhas tudo. Oh, roubaram minhas galinhas tudo, não saia da minha casa pedindo as coisas... deve ser terrivel porque isso não é vida de gente viver. Você fala que mulher rural é luta, pelo menos você tem dignidade, você tá em cima do que é seu, tá lutando... Vai panhá as coisas dos outros pra viver?! Eu acho que isso é horrivel, Deus me livre. Concordo com isso não. Ah, eles chegam pedindo, se você 
não der... Eu não gosto de cigano não. Eu tenho medo de cigano". (Mulher rural, 40 anos).

"Já fecharam a porta... nós xingamos elas todas... aquela coisa foi subindo na gente. Deu aquela raiva e a gente xingou ela toda. Nós pedimos um pouco de água e ela disse "não tem não". Fechou a porta. De novo: "A senhora podia arranjar um pouco de água pra nós?”. Ela fechou a porta... Ai nós de novo. "Vem cá, o que a senhora tem contra nós? É racismo! A senhora sabia que a senhora poderia ir presa?" Aí ela... "Não calma, eu tô com meu marido doente". Pura mentira. Xingamos ela todinha..." (Mulher cigana, 19 anos).

b) Representações sobre endo e exogrupo: homens e mulheres

O conteúdo do discurso das mulheres sobre as diferenças entre os grupos sofreu atenuações ao longo das entrevistas. Ao avaliar seu modo de vida frente ao domínio masculino, verificamos pontos de identificação baseados na condição feminina, que é muito semelhante nos dois grupos. Ressaltamos que, especificamente no grupo cigano, uma das participantes relatou a prática de exclusão das crianças do sexo feminino.

"A gente tem que dar valor a gente, né não? Ser mulher pra mim, a gente tem que dar valor pra gente. Cigano, tinha um lado de cigano há um tempo atrás, eles não gostavam de ter mulher. Você pode olhar que tem muita gente cigana que não é criada por cigano. Eles dá as filhas porque eles não gostam, gostam mais de macho, entendeu?" (Mulher cigana, 19 anos).

"Que a mulher na sociedade hoje ela é ainda discriminada, ainda não tem muita vez na sociedade e a mulher tinha que ter esse direito... tanto na politica, quanto no sindicato, como na comunidade, como no grupo de mulher, em qualquer instituição". (Mulher rural, 52 anos).

A descrição dos papéis femininos (responsabilidade com os filhos; com a casa/barraca; com o trabalho doméstico) traduz o cotidiano dessas mulheres que, apesar das diferenças, acabam estabelecendo práticas de solidariedade.

"Andava o dia todo, com os meninos. Depois, chegava tarde e tinha que fazer comida. Trabalhava o dia todo... Às vezes, ganhava neném num dia e no outro viajava" (Mulher cigana, 67 anos).

"É sofrida. Por quê? Você vê, eu comecei isso aqui trabalhando na roça, criando esses meninos, lutando pra estudar eles... quantas vez, eu pegava eles e levava nas casas de farinha de madrugada... pra poder sobreviver. É dificil" (Mulher rural, 64 anos). 
"Ela me xingou... porque ela queria três galinhas, mas eu não podia dar, dei uma porque ela falou que era pra mulher que tinha ganhado neném" (Mulher rural, 54 anos).

Neste último caso, estamos diante de um encontro diferente. O confronto entre a cigana e a mulher rural estabelecido inicialmente é re-significado pela presença da maternidade: não é apenas uma camponesa diante de uma cigana, mas duas mulheres-mães. A identificação promovida pela maternidade leva a mulher rural a reavaliar sua prática e finalmente ajudar a cigana que havia tido seu bebê recentemente.

$\mathrm{Na}$ comparação entre os grupos, a condição feminina vivenciada por essas mulheres na relação com os homens é caracterizada pela subordinação, exploração e sofrimento.

"Eu acho que a cigana é outra mulher que é também explorada porque a mulher cigana fica a serviço dos homens. Elas ficam nas casas dos outros pedindo as coisas dos outros para tratar dos homens que fica em casa dormindo, fica andando a cavalo o dia todo. Então, são mulheres exploradas como nós também somos, mas elas não tem assim, uma casa... pode tá grávida, com menininho recém nascido, elas são obrigadas a muntar naqueles cavalos, cozinha naqueles negócios tudo sujo debaixo das barracas. Então, eu acho que são mulheres exploradas mais do que nós ainda. Eu nunca concordei... eu não sei se elas gostam dessa vida, ou são obrigadas a ser assim... mas são mais exploradas ainda do que nós as mulheres ciganas... debaixo de chuva, aqueles trem tudo que molha, aquela sujeira..." (Mulher rural, 59 anos).

"A vida da mulher não é boa não. Tem umas que é boa. Tem umas que não é. Tem umas que sofre mais, tem umas que não sofre. A mulher é sofrida. Elas trabalha na roça... Já lutei muito nessa vida" (Mulher cigana, 67 anos).

No entanto, a aspiração que resulta de tais relações é a de construção de relações mais igualitárias:

“... eu mudaria pras mulher virar homem e os homens ficar homens mesmo" (Mulher cigana, 16 anos).

"Somos tudo igual, mulher cigana e rural... é a mesma coisa da gente" (Mulher cigana, 19 anos).

"Eu acho que todas as mulheres são igual. Às vezes, tem até uma maneira diferente de pensar, mas tudo quase que uma sente, a outra sente também. Eu acho que é a mesma coisa. A gente sente a mesma coisa" (Mulher rural, 56 anos). 
c) A dinâmica intergrupal: entre a casa e a barraca

A construção dessas representações orienta práticas conflituosas entre os grupos, como o fechar a casa pelas mulheres rurais e o lançar praga pelas ciganas. A dinâmica grupal "entre a casa e a barraca" traduz a vivência concreta entre essas mulheres que são convocadas a avaliar suas ações frente à presença de um outro necessário e/ou perigoso.

Todas as mulheres rurais, quando perguntadas sobre a forma como seriam tratadas caso fossem às "barracas ciganas", relataram que imaginavam que seriam bem tratadas -

"Seria bem recebida porque quando a gente chega na barraca das ciganas, elas chamam pra dentro, dá cafezinho, trata a gente bem mesmo".

Duas expectativas são enunciadas pelas mulheres ciganas quanto à mesma questão, se fossem às "casas rurais": uma com o acolhimento pelo grupo rural como resposta à sua cordialidade -

"Acho que seria bem tratada porque nós tratamos bem"

- e outra segundo a clássica atitude do fechar a casa às mulheres ciganas -

"Seria tratada mal, fecha a porta... Tratam a gente mal. Acham que somos bicho."

Quando os dois grupos são convidados a pensar como elas receberiam umas às outras, relataram as mesmas situações: a mulher cigana acolheria a mulher rural -

"Nós tratava bom. Chamava pra dentro e oferecia um cafezinho"

- e algumas mulheres rurais trancariam as casas e não as receberiam -

"Eu fico com pé atrás... Eu pego e tranco a casa"

-, enquanto outras disseram que

"Trataria bem, mas não chamaria pra dentro de casa...".

É interessante que todas as mulheres rurais enfatizaram que não permitiriam a presença de uma cigana dentro de casa, como se este fosse um espaço sagrado que pudesse ser profanado pela simples presença de uma mulher cigana.

d) Ancoragens do medo de ciganos

Especificamente quanto ao medo de ciganos, encontramos na base de sua construção a imagem da maldição difundida pelos primeiros moradores da comunidade, servindo para explicar hábitos e práticas típicas do grupo 
cigano, bem como justificar os maus acontecimentos vividos pela comunidade, como o aparecimento de piolhos, por exemplo:

"Os antigos falavam que os ciganos eram amaldiçoados, por isso que passava... Cigano não ficava num lugar só. Cigano não tinha lugar pra trabalhar, que era a maldição deles andar... Cigano é povo amaldiçoado! Falam que se eles ficarem mais de oito dias, eles dão bicho. Quando apareceu piolho na comunidade, falaram que foi os ciganos!" (mulher rural, 52 anos).

Na condição de povo amaldiçoado, os ciganos passam a ter o poder de fazer o mal através das "pragas", que são combatidas por meio dos recursos também místicos das rezas cristãs.

"Eu sinto um medo assim, que eles vêm... e sei lá, um medo assim que elas podem fazer mal a gente. Tem cigana que vem e faz medo mesmo. Elas podem fazer mal a gente. Elas pedem uma coisa, se a gente nega, elas joga praga... fala que faz isso, fala que faz aquilo. A gente sente assim, um medo... Mas ai a gente segue em frente e se apega com Deus e Nossa Senhora, que isso não pega na gente" (Mulher rural, 65 anos).

Em contrapartida, as mulheres ciganas percebem a elaboração e difusão dessa imagem negativa como um preconceito:

"A gente sentia que eles tinha medo da gente. Que a gente vai conversar com uma pessoa e a pessoa não quer conversar com a gente, deve ter algum efeito. Ou medo ou algum... “compreceito"... "compre”... "preconceito"." (Mulher cigana, 38 anos).

A construção dessas representações foi nutrida ao longo das gerações pelos grupos rural e cigano, sendo, a cada época, acrescentadas novas "evidências" do efeito negativo da presença dos ciganos na comunidade e da falta de acolhimento, em função do preconceito das mulheres rurais. É importante ressaltar ainda que a gênese dessa imagem está historicamente situada nos primórdios do desenvolvimento da comunidade rural, época repleta de dificuldades. A comunidade não possuía meios para se manter, a fome era uma ameaça constante para o grupo e os conflitos entre os grupos rural e cigano também decorriam da disputa pelos escassos recursos disponíveis.

\section{Discussão}

$\mathrm{O}$ encontro entre a comunidade rural e a comunidade cigana acontece principalmente através das mulheres. Essa condição marca a importância de ouvirmos as representantes do universo feminino destes grupos, pois entendemos que a compreensão dos indivíduos está vinculada 
"ao conhecimento de suas experiências, de suas relações com a realidade, determinadas em grande parte pela sua inserção social e pela sua apreensão e interpretação da realidade" (Trindade, 1996, p. 47).

As discussões acerca do domínio feminino na esfera doméstica não são novidade (Lamphere, 1979; Perrot, 1998; Viana, 1999). O modelo tradicional das relações de trabalho em que o homem realiza a atividade econômica central como "o provedor", aquele que irá garantir a sobrevivência da família, enquanto a mulher cuida da casa e dos filhos, se reproduz nas relações de gênero encontradas no modo de vida rural, apesar de a mulher também desempenhar a função de trabalhadora rural nas atividades agrícolas da família (Brumer, 1996). Em contrapartida, em muitas comunidades ciganas, são as mulheres as responsáveis pela conquista diária do dinheiro através das leituras das mãos e as principais responsáveis pelo cuidado dos filhos (Teixeira, 2001), embora sejam os homens ciganos os detentores do poder na relação com as mulheres. No grupo cigano que pesquisamos, apenas a primeira geração ainda mantém a prática de leitura das mãos. A responsabilidade das ciganas da segunda e terceira gerações compreende as atividades ligadas ao cuidado com os filhos e com a barraca, ainda que durante as "viagens" seja função delas realizar a visitação nas casas, a fim de conseguir comida para o grupo.

O território rural é o principal cenário onde acontecem os encontros entre as mulheres ciganas e rurais, uma vez que são as ciganas que realizam as visitações às casas, enquanto os homens permanecem nas barracas e, no caso do grupo rural, os homens passam o dia prioritariamente nas lavouras e as mulheres ficam em casa com maior freqüência. Os encontros no território rural são geralmente marcados pelo conflito e por práticas excludentes, como o fechar a casa, orientadas pelo medo de ciganas. Por outro lado, o encontro entre as mulheres nas barracas é caracterizado pela cordialidade, visto que funciona como uma estratégia para promover a aceitação do grupo de ciganos pela comunidade rural. Ao serem cordiais, as mulheres ciganas mostram às outras uma característica positiva de seu próprio grupo. Entender essa dinâmica é interessante, pois são espaços que operam como

"entidades morais, esferas de ação social, províncias éticas dotadas de positividade, domínios culturais institucionalizados e, por causa disso, capazes de despertar emoções, reações, leis" (DaMatta, 1987, p. 15).

Os resultados obtidos através do ALCESTE e da Análise de Conteúdo permitem discutir a relação intergrupal a partir da presença de conflitos decorrentes da identificação como "mulheres ciganas" ou "mulheres rurais". No entanto, verifica-se também um processo de identificação mais amplo de ambos os grupos de mulheres, ciganas e rurais, com a categoria de gênero 
"nós mulheres", processo este baseado na solidariedade decorrente das relações de gênero que predominam e são semelhantes em ambos os grupos.

As relações de conflito intergrupal estão orientadas pelas representações sobre o exogrupo, formadas principalmente por conteúdos negativos. A representação do exogrupo cigano está ligada ao sentimento de medo e à idéia dos ciganos como povo amaldiçoado e capaz de fazer o mal. Dados semelhantes foram encontrados por Silva e Silva (2000) acerca das representações e práticas negativas dirigidas às comunidades ciganas portuguesas. Silva, Sousa, Oliveira e Magano (2000) discutem que essas representações, constituídas de elementos negativos, estão a tal ponto interiorizadas, que muitos ciganos recusam a nomeação "cigano", buscando igualmente se distanciar de traços identificadores da diferença, como o vestuário e penteados.

"Como se não se pudesse ser cigano e integrado na sociedade dominante a ponto de a identidade não ser exteriormente visível. Como se ser cigano exija ser portador das marcas visíveis da exclusão. Como se ser cigano implique ser excluído" (p. 01).

As representações do exogrupo rural, por sua vez, aparecem de forma pouco clara no discurso cigano, indicando uma estratégia grupal que segue a lógica de construção das identidades sociais que favorece uma "auto-imagem positiva". Nesta perspectiva o indivíduo busca preservar "uma imagem positiva de si próprio e é pela competição social entre grupos, que tende à valorização do grupo de pertença em relação a outros grupos, que o indivíduo esperaria esta auto-avaliação positiva" (Doise, Deschamps \& Mugny, 1980, p. 46).

Quando analisamos as representações do endogrupo, tanto das mulheres ciganas como das mulheres rurais, identificamos apenas elementos carregados de sentidos positivos, conforme esperado, pois o grupo social "é visto como tendo por função munir os seus membros duma identidade social positiva" (Tajfel, 1983, p. 258).

Os grupos são marcadamente fechados e as diferenças indicadas no discurso de ambos os grupos estão alicerçadas numa estrutura identitária construída a partir de um conjunto de crenças que alimentam as práticas dirigidas aos exogrupos. Entretanto, as relações de gênero parecem superar as diferenças étnicas e promover a identificação entre elas: na oposição aos homens, as mulheres ciganas e rurais se reconhecem com endogrupo e os homens, por sua vez, passam a constituir o exogrupo. São elas que desempenham os papéis domésticos, cuidam dos filhos, são responsáveis pela casa e pela barraca, e conduzem suas vidas de forma mais rígida segundo as normas dos grupos. Neste ponto de encontro, as diferenças étnicas se diluem e dão lugar à gestação da identidade feminina, através de mútua identificação nas relações de gênero, onde a condição da mulher rompe a 
muralha do medo e do preconceito. Elas se solidarizam e constroem o discurso da igualdade. Este processo indica que tanto as mulheres ciganas quanto as mulheres rurais são indivíduos que possuem formas de vida muito semelhantes, especialmente na relação com os homens, que nestes grupos são detentores de autoridade e poder.

Os dados obtidos no presente estudo mostram que no nosso cotidiano nos associamos a diferentes grupos sociais rural, cigano, homens, mulheres -, assumindo, portanto, diferentes identidades (Andrade, 1998; Hogg e outros, 2004). A construção e a transformação da identidade evidenciadas pelos dados ocorrem através de um processo contínuo de identificação no qual o indivíduo vai se constituindo e se transformando. Na base deste processo estão as relações sociais que o indivíduo estabelece com um "outro" que, sempre pluralizado, dinamiza as diversas situações de pertencimento.

As relações intergrupais se configuram em meio a uma complexa rede de significados e práticas construídos e mantidos por lógicas que demandam formas multidimensionadas de análise. Através dos recursos utilizados no presente trabalho, pudemos conhecer como os grupos de mulheres rurais e ciganas vivem e representam a si mesmas e ao outro grupo. Foi possível identificar que tais representações são mediadas por sistemas de crenças que produzem a identidade de oposição que, fundamentada nas diferenças existentes entre os grupos, favorece o surgimento de comportamentos excludentes; por outro lado, em função da vivência semelhante de relações de gênero, verificamos a emergência da identidade de "mulheres", compartilhada por ambos os grupos, o que torna possível o exercício de práticas solidárias entre as mulheres ciganas e rurais.

\section{Referências}

Andrade, M. A. A. (1998). A identidade como representação e a representação da identidade. In A. S. P. Moreira \& D. C. Oliveira (Orgs.), Estudos interdisciplinares de representação social (pp. 141-149). Goiânia: AB editora.

Bardin, L. (2002). Análise de conteúdo. Lisboa: Edições 70. (Trabalho original publicado em 1977).

Bauer, M. W. (2002). Análise de conteúdo clássica: uma revisão. In M. W. Bauer \& G. Gaskell (Orgs.), Pesquisa qualitativa com texto, imagem e som: um manual prático (pp. 189-217). Petrópolis: Vozes.

Bonin, L. F. R. (2000). Indivíduo, cultura e sociedade. In M. G. C. Jacques, M. N. Strey, N. M. G. Bernardes, P. A. Guareschi, S. A. Carlos \& T. M. G. Fonseca (Orgs.), Psicologia social contemporânea. Petrópolis: Vozes.

Breakwell, G.M. (1993). Social Representations and Social Identity. Papers on Social Representations, 2 (3), pp. 198-217. 
Brumer, A. (1996). Mulher e desenvolvimento rural. In C. Presvelou; F. R. Almeida \& J. A. Almeida (Orgs.), Mulher, família e desenvolvimento rural. Santa Maria: Edições da UFSM.

Calil, M. I. (2003). De menino de rua a adolescente: análise sócio-histórica de um processo de ressignificação do sujeito. In S. Ozella (Org.), Adolescências construídas - a visão da psicologia sócio-histórica (pp. 136-166). São Paulo: Cortez.

Casas, F. (2005). Desafios atuais da Psicologia na intervenção social. Psicologia \& Sociedade, 17 (2), 42-49.

Cuvello, S. T. V. (2004). Representação social de adolescente sobre o "viciado" in drogas. Dissertação de Mestrado, Universidade Federal do Espírito Santo, Vitória.

DaMatta, R. (1987). A casa \& a rua: espaço, cidadania, mulher e morte no Brasil. Rio de Janeiro: Editora Guanabara.

Del Priore, M. \& Venâncio, R. (2006). Uma história da vida rural no Brasil. Rio de Janeiro: Ediouro.

Doise, W., Deschamps, J., \& Mugny, G. (1980). Psicologia social experimental. Lisboa: Moraes Editores.

Flick, U. (2004). Uma introdução à pesquisa qualitativa. Porto Alegre: Bookman.

Geertz, C. (1989). A interpretação das culturas. Rio de Janeiro: LTC Editora.

Guareschi, P. (1998). Alteridade e relação - uma perspectiva crítica. In D. Jodelet, S. Jovchelovitch, G. Duveen, H. Joffe, N. Morant, D. Rose \& P. Guareschi (Orgs.), Representando a alteridade (pp. 149-161). Rio de Janeiro: Vozes.

Greenland, K., \& Brown, R. (2000). In D. Capozza \& R. Brown (Orgs.), Social identity processes (pp. 167-183). London: Sage Publications.

Hogg, M. A. e outros. (2004). The social identity perspective: intergroup relations, self-conception, and small groups. Small Group Research, 35 (03), 246-276.

Jodelet, D. (1998). A alteridade como produto e processo psicossocial. In A. Arruda (Org.), Representando a alteridade (pp. 47-67). Rio de Janeiro: Vozes.

Jodelet, D. (2001). Representações sociais: um domínio in expansão. In D. Jodelet (Org.), As representações sociais (pp. 17-44). Rio de Janeiro: EdUERJ.

Jodelet, D. (2005). Loucuras e representações sociais. Rio de Janeiro: Vozes.

Joffe, H. (1995). Eu não, o meu grupo não - representações sociais transculturais da aids. In P. Guareschi \& S. Jovchelovitch (Orgs.), Textos em representações sociais (pp. 297-322). Rio de Janeiro: Vozes.

Lamphere, L. (1979). Estratégias, cooperação e conflito entre as mulheres em grupos domésticos. In M. Z. Ronaldo \& L. Lamphere (Orgs.), A mulher, a cultura e a sociedade (pp. 121-140). Rio de Janeiro: Paz e Terra.

Martins, P. O. (2002). As expectativas do ter e o fracasso do ser: representações sociais de adolescência e suicídio entre adolescentes. Dissertação de Mestrado, Universidade Federal do Espírito Santo, Vitória.

Menandro, M. C. S. (2004). Gente jovem reunida: um estudo de representações sociais da adolescência/juventude a partir de textos jornalísticos (1968/1974 e 
1996/2002). Tese de Doutorado em Psicologia, Universidade Federal do Espírito Santo, Vitória.

Mendes, M. M. (2000). Um olhar sobre a identidade e a alteridade: Nós, os Ciganos e os Outros, os Não Ciganos. Anais do IV Congresso Português de Sociologia. Coimbra: Associação Portuguesa de Sociologia.

Moscovici, S. (1978). A representação social da psicanálise. Rio de Janeiro: Zahar. (Trabalho originalmente publicado in 1961).

Nascimento, A. R. A. (2004). Memória dos verdes anos: saudade da infância na música popular brasileira - uma investigação e uma proposta de análise de dados. Tese de Doutorado, Universidade Federal do Espírito Santo, Vitória.

Nicolaci-da-Costa, A. M. (1989) Questões metodológicas sobre a análise de discurso. Psicologia Reflexão e Crítica, 4 (1/2), 103-118.

Perrot, M. (1998). Mulheres públicas. São Paulo: Editora UNESP.

Reinert, M. (1990). Alceste, une méthodologie d'analyse des données textuelles et une aplicattion. Aurelia de Gerard de Nerval. Bulletin de methodologie sociologique, 24-54.

Ribeiro, M. A. S. (2005). Os homossexuais em busca de visibilidade social. Tese de Doutorado em Psicologia, Universidade de Brasília, Brasília.

Silva, L. F., Sousa, F., Oliveira, L., \& Magano, O. (2000). A Comunidade Cigana e o Etnocentrismo da Instituição Médica de Saúde Comunitária. Anais do IV Congresso Português de Sociologia. Coimbra: Associação Portuguesa de Sociologia.

Silva, M. C., \& Silva, S. (2000). Práticas e representações sociais face aos ciganos O caso de Oleiros, Vila Verde. Anais do IV Congresso Português de Sociologia. Coimbra: Associação Portuguesa de Sociologia.

Souza, L. (2004). Processos de categorização e identidade: solidariedade, exclusão e violência. In L. Souza \& Z. A. Trindade (Orgs.), Violência e exclusão: convivendo com paradoxos (pp. 57-74). São Paulo: Casa do Psicólogo.

Tajfel, H. (1982). Grupos humanos e categorias sociais I. Lisboa: Livros Horizonte.

Tajfel, H. (1983). Grupos humanos e categorias sociais II. Lisboa: Livros Horizonte.

Teixeira, R. C. (2000). História dos ciganos no Brasil. Recife: Núcleo de Estudos Ciganos.

Trindade, Z. A. (1996). Representação social: "modo de conhecer" no cenário da saúde. In Z. A. Trindade \& C. Camino (Orgs.), Cognição social e juízo moral (pp. 45-59). Vitória: ANPEPP.

Viana, T. C. (1999). A comédia humana, cultura e feminilidade. Brasília: UnB. 